\title{
Investigation and Reflection on the University-enterprise Cooperation Problem in the Western Region of China
}

\author{
He Yong; Zhang Yichun \\ Department of Economics and Trade, Guilin University of Aerospace Technology, Guilin Guangxi 541004
}

\begin{abstract}
The university-enterprise cooperation is the only way to the professionalization of higher education and the cultivating model of skilled talents at the same time. Now, colleges and universities in the western region of China are trying to promote the university-enterprise cooperation, while this kind of cooperation is facing great difficulties and challenges. Based on the field and questionnaire survey, the paper analyzes the form and the way of the current university-enterprise cooperation in the western region of China, as well as difficulties and challenges occurred. Meanwhile, based on the result of the survey, the paper puts forward the "dynamic factor analytic method" which should be adopted by the university-enterprise cooperation. In the end, based on the "dynamic factor analytic method", the paper makes 3 suggestions in order to improve the strategy and the way of the university-enterprise cooperation in the western region of China and to promote its effect.
\end{abstract}

Keywords: the western region; university-enterprise cooperation; influencing factors; cooperation mode

\section{Introduction}

With the arrival of the popularization stage of China's higher education, vocational education in colleges and universities also enters into a rapid development period and higher vocational education in the western region also ushers new opportunities of development. The Outline of National Medium and Long-term Education Reform and Development Plan (2010-2020) published in 2010 requires that higher education need to optimize structure and have characteristics, meet the social development demands of national and regional economy, and optimize regional layout structure to implement higher education revitalization plan in the Midwest. At the same time, it puts forward a plan to develop the modern vocational education system and attaches great importance to the coordinated development of industry enterprises and higher vocational colleges, "establishing perfecting university-running mechanism of government domination, industry guidance, and enterprise participation, formulating the running university regulations which promote the university-enterprise cooperation, and promoting the institutionalization of universityenterprise cooperation ". University-enterprise cooperation, as an important part of the plan of higher education revitalization in the western region, is an important measure for colleges in the western region to solve prominent problems in the education reform and development and embodies the essence of higher education.

However, the university-enterprise cooperation in the western region, compared with the developed eastern areas of China, presents different effect and faces enormous difficulties and challenges. In this paper, on the basis of field investigation and questionnaire survey, it has analyzed the form, path, as well as the existing difficulties and challenges of the current cooperation between colleges and enterprise in the western region of China. At the same time, on the basis of research results, this paper puts forward that the university-enterprise cooperation should adopt the "dynamic factor analysis".

\section{Research and Analysis on University- enterprise Cooperation in the Under- developed Western Region of China}

\subsection{The Research Sample}

In this paper, the research is aimed at the case of the university-enterprise cooperation in Guangxi. Ten colleges in Nanning, Guilin and Liuzhou are selected as research samples; parts of them are universities; parts are higher vocational colleges. Several enterprises which are closest to 10 colleges are selected as surveyed enterprise samples and data sources are merged into enterprise validation questionnaire. The surveyed enterprise affiliated industries include food, chain business, transportation, hotel, real estate, building materials, medicine, mechanical and electrical industry, agricultural products processing etc. The key information of enterprises in the questionnaire survey includes scale, industry, and whether there is a government funded on the project of ownership types. The survey, which runs from January 2011 to March 2011, distributes 160 questionnaires and returns 95 questionnaires including 88 valid questionnaires. Efficiency rate and recovery rate is respectively $59.7 \%$ and $92.6 \%$. 
Table 1. The Enterprise Scale of University-enterprise Cooperation

\begin{tabular}{|c|c|c|c|c|c|}
\hline Scale & Number & Percentage & Ownership type & Number & Percentage \\
\hline $\begin{array}{l}\text { Registered capital over } \\
500 \text { million Yuan }\end{array}$ & 13 & 14.8 & $\begin{array}{l}\text { State-owned } \\
\text { enterprises }\end{array}$ & 10 & 11.3 \\
\hline $\begin{array}{l}\text { Registered capital of } \\
500,000-5 \text { million Yuan }\end{array}$ & 28 & 31.8 & Joint-stock & 25 & 28.4 \\
\hline $\begin{array}{l}\text { Registered capital below } \\
500,000 \text { Yuan }\end{array}$ & 47. & 53.4 & Private enterprise & 53 & 60.3 \\
\hline
\end{tabular}

Table 2. Enterprise Affiliated Industries of University-enterprise Cooperation

\begin{tabular}{lcc}
\hline $\begin{array}{l}\text { Enterprise affiliated industries of } \\
\text { university-enterprise cooperation }\end{array}$ & Number & Percentage \\
\hline Food & 5 & 5.6 \\
Chain & 16 & 18.1 \\
Machine and electricity & 15 & 17.0 \\
Hotel and tourism & 18 & 18.1 \\
Real estate & 4 & 4.5 \\
Building materials & 6 & 6.8 \\
Agriculture & 24 & 27.2 \\
\hline
\end{tabular}

Table 3. Enterprises of University-enterprise Cooperation Accepting Fund

\begin{tabular}{lcc}
\hline Technology center type & Number & Percentage \\
\hline National funded project & 14 & 15.9 \\
Provincial funded projects & 24 & 27.2 \\
Municipal funded projects & 26 & 29.2 \\
others & 24 & 27.2 \\
\hline
\end{tabular}

It can be found from table 1 that the main force participating in cooperation of university-enterprise is small and medium-sized enterprises and even miniature enterprises. It is also the basic situation of university-enterprise cooperation in the western region, and has not formed a similar Ningbo vocational and technical college cooperation with Haitian, which has influential brands and representatives of universityenterprise cooperation throughout the country. In addition, with the analysis of statistical results, we can conclude that the main cooperation object of large enterprises is undergraduate course colleges and small and medium-sized enterprises mainly cooperate with higher vocational colleges. It suggests that enterprises choose suitable partners according to their own needs.

From the analysis of table 2, it can be found that industries participating in the university-enterprise cooperation have different levels. More agricultural product processing enterprises participate and it reflects that the economy agriculture occupies a more important position in Guangxi, which shows that the cooperation is closely combined with local industry characteristics, and is conducive to the further university-enterprise cooperation. Enterprises, such as hotels, tourism, will be more willing to participate in the university-enterprise cooperation, which shows that the university-enterprise cooperation which can directly bring benefits for enterprises is more attractive to enterprises.

From the analysis of table 3 , it can be found that enterprises having received project support by the nation or local government are more willing to participate in university-enterprise cooperation, because these enterprises have stronger sense of social responsibility and are more willing to respond to the call of the government to participate in university-enterprise cooperation.

\subsection{The Form of University-enterprise Cooperation in the Western Region}

In this survey of the form of enterprise and colleges cooperation, the main options are as follows: a. cooperation in running schools (including ordering cultivation and enterprise participation or independent schools), b. cooperative research and development, c. commission development of horizontal topic and management consulting of enterprise, d. enterprise entrusting personnel training, e. organized bidding for major projects and research and development, $f$. technology transfer, g. field training. In this problem questionnaire, the author divides it into two parts when counting: the choice results of enterprises and the choice results of colleges. Among them, the survey results of enterprises' choice suggest that: the three forms of cooperation that the enterprises are most willing to choose are "research and development of cooperation", $82.5 \%$, the highest proportion and "cooperative research" is one of the most popular way with the enterprises, which is the most effective way, for example, Guilin University of Electronic Science and Technology, 
in cooperation with China Rubber Chemical LTD, develops "all-steel radial giant engineering machinery tire" to create benefits about hundreds of millions Yuan for the enterprise; "enterprise entrusting personnel training”, 82.9\%, and “commission development of horizontal topic and management consulting of enterprise”, 74.4\%; the survey results of colleges' choice suggest that the three forms of cooperation that colleges are most willing to take are field training, $100 \%$, cooperative research, $74.5 \%$, technology transfer, $68.5 \%$. From the analysis of above results, the form of university-enterprise cooperation seemingly varies, and it essentially reflects their demands. Enterprises are fond of technology transfer and personnel training, and it reflects enterprises' need based on labor and technology. Colleges prefer cooperation forms of field training and technology transfer, which conforms to the two cooperation purposes of colleges based on talent cultivation and improvement of scientific research innovation ability.

\subsection{The Basic Route of University-enterprise Cooperation in the Western Region}

The basic route of university-enterprise cooperation actually refers to the two sides of the subject relationship of university-enterprise cooperation (enterprises and colleges) through a certain way to build relationships, and university-enterprise cooperation path can be divided into direct and indirect path.

The so-called direct path is shown in figure 1 . Schools and enterprises establish the direct ways to cooperate according to their interests, that is, one side contacts the other side actively, and then they establish a long-term relation of cooperation. According to the survey: in the process of direct path establishment, enterprises take the initiative to contact less, only $12.3 \%$, and it reflects that the cooperation motivation of enterprises is insufficient; the enterprises take the initiative to contact colleges mainly in higher levels of university such as Guangxi University, Guilin University of Electronic Science and Technology, and it shows that enterprises of university-enterprise cooperation with interest drive pay more attention to the reputation and technology research ability. Colleges take the initiative to contact more, accounting for about $87.7 \%$, which on the other hand proves the main body form of university-enterprise cooperation in the western region is colleges-based cooperative mode.

The so-called indirect path is shown in figure 2 . Sometimes the cooperative relationship between colleges and enterprises is not direct, and they regard the government as "intermediary", and the cooperation path changes from "direct" to "indirect". According to the sample survey statistics, university-enterprise cooperation promotes and builds very little through the government promotion, only $20.5 \%$, far less than eastern developed areas. From the current Guangxi adopting policies, such as the advocacy of "service of colleges for Guangxi local economic development" activities, university-enterprise cooperation ratio of indirect path will rise in the future.

\section{Enterprises in the Western Region Carry}

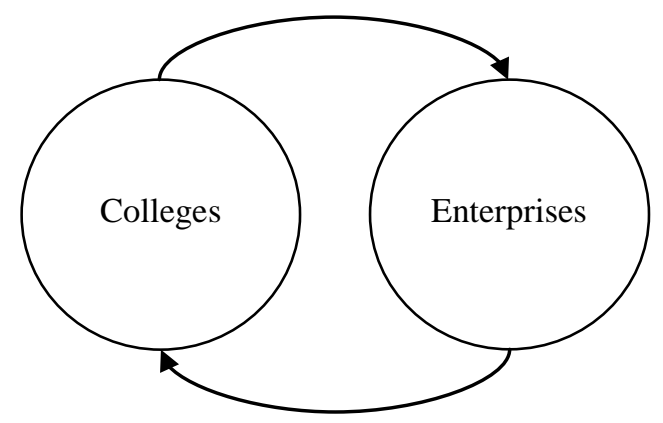

Figure 1. Direct Path

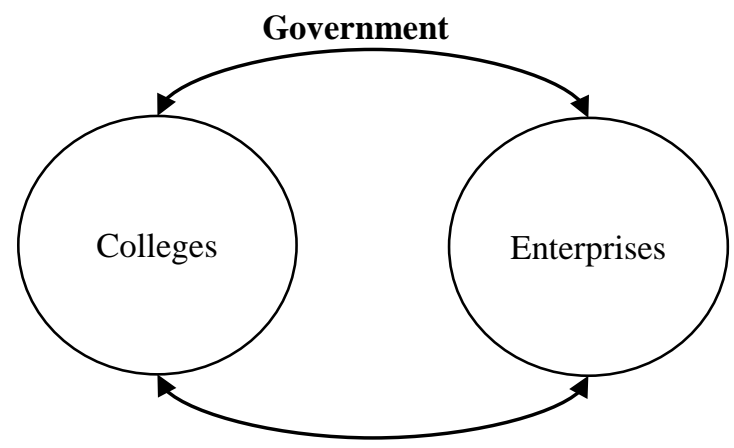

Figure 2. Indirect Path

\section{out Dynamic Factor Analysis of University- enterprise Cooperation}

The cooperation of enterprises and colleges is based on the fitness of interest which is the premise and key to form the university-enterprise cooperation, and interest and the social responsibility constitute the two basic elements of university-enterprise cooperation. With different properties, the two sides have different interests, so university-enterprise cooperation need find interest cooperation, namely the power of cooperation.

\subsection{Motivation Factor Analysis of the Colleges in University-enterprise Cooperation}

When the questionnaire is designed, it set motivation factors of university-enterprise cooperation in higher education:

A. Improve the cultivation quality of skilled talents;

$B$. Expand the school profile and promote social service ability;

C. Get information of personnel need and part-time teachers, and other important resources;

D. Get enterprise funds, equipment, establish practice base and employment base in the enterprises, promote students employment;

E. Track new technologies, new processes and new jobs of enterprises, such as dynamic changes, improve teachers' scientific research ability;

F. Introduce enterprise culture; promote students professional ethics and professional quality, etc.

In the recycling 88 valid questionnaires, statistical results display (figure 3 ): the choice of "improve the cultivation quality of skilled talents”, $100 \%$, it suggests that core power on cooperation of university-enterprise is to improve the personnel training quality; the choice of "expand the school profile and promote social service ability”, 75.6\%, (including 94.3\%of the undergraduate 
colleges), it suggests that undergraduate course colleges attach great importance to enhance our influence, and emphasize to improve the social service ability; the choice of " Get information of personnel need and part-time teachers, and other important resources", $66.4 \%$, (accounting for an absolute advantage of $100 \%$ selecting rate in higher vocational colleges), it suggests that it has not enough money to run in higher vocational colleges and need more government support, at the same time, higher vocational colleges pay more attention to practical training base construction, to practice ability, and it conforms to the current characteristic of vocational education colleges oriented employment.

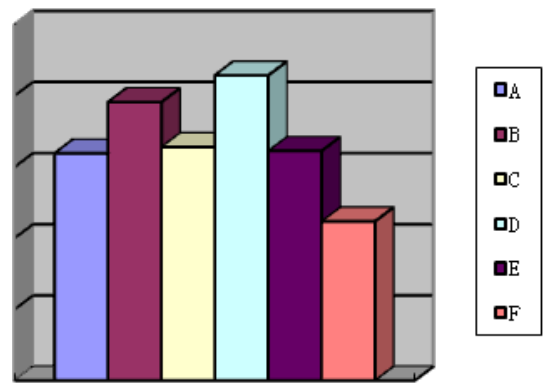

Figure 3. Motivation Factor Statistics of Colleges' Cooperation

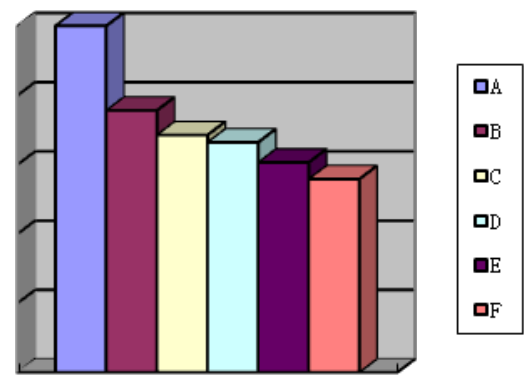

Figure 4. Motivation factor statistics of enterprises' cooperation

\subsection{Motivation Factor Analysis of Enterprises in University-enterprise Cooperation}

The motivation factors of the enterprises in universityenterprise cooperation in the designing questionnaire mainly are:

A. Obtain high-skilled personnel support that enterprises need;

B. The market needs;

C. Improve the level of enterprise technology and development capability, use the resources of colleges to carry out the corporate training;

D. In cooperation with colleges to carry out scientific research and technological innovation;

E. Give priority to obtaining the transformation of scientific research achievements;

$F$. The social responsibility, corporate public relations, the government encourage;

Statistical results of motivation factors of the enterprises in university-enterprise cooperation show (see figure 4) that motivation factors of enterprises participating in university-enterprise cooperation mainly involve technology, market and talent. The choice of "in cooperation with colleges to carry out scientific research and technological innovation” is $85.7 \%$; the choice of " improve the level of enterprise technology and development capability, use the resources of colleges to carry out the corporate training" is $65.6 \%$; the choice of " obtain high-skilled personnel support that enterprises need" is $63.8 \%$, and the choice of " the social responsibility, corporate public relations, the government encourage" is $44.7 \%$, which suggests that there is big room for government to influence enterprises to enhance university-enterprise cooperation. This shows that enterprises in cooperation with colleges want to obtain technology first, talent second, government preferential policies and support last. From current status of university-enterprise cooperation in the western region, it exists a situation of "colleges are popular, enterprises are not”. If this situation is to be changed, we must make the enterprise obtain the preferentiality such as "technology, talent and government support” in university-enterprise cooperation, so enterprises are glad to attend the universityenterprise cooperation. Therefore, colleges must promote technology innovation and social service ability and train talents in accord with the actual requirement of enterprises, at the same time, the government should play a bigger role in university- enterprise cooperation.

\section{University-enterprise Cooperation Sug- gestions based on the Dynamic Factor Analysis}

Through the dynamic factor analysis of universityenterprise cooperation in the western region of China in the third quarter, in order to improve the strategy and way of university-enterprise and promote the cooperation effect of university-enterprise in China's western areas, we put forward three referenced suggestions.

\subsection{University-enterprise Cooperation Mode in the Western Region Gives Priority to Colleges}

Higher education in the western region under the force of the government develops rapidly with the main characteristics of scale expansion. In the process of this development, enterprises and colleges belong to different systems and different interests, which will position itself out of the education system, lacking the tradition and motivation of participation in education. Colleges in the western region should, with the influence of the domestic and foreign advanced teaching ideas and thoughts, comply with the laws of education itself and seek the road of university-enterprise cooperation. In the process of establishing relationship of university-enterprise cooperation, colleges in the western region need to take initiative and bear the main responsibility of cooperation. The enterprises play a passive role in cooperation with college education, and university-enterprise cooperation in the western region gives priority to colleges.

\subsection{Colleges Take Connotative Development Way, and Strengthen the Cooperation Base}

The core interests of enterprises are to maximally get 
investment income in university-enterprise cooperation, at the same time there are needs about technological innovation, product quality and talent training. Therefore, the point of colleges enhancing attraction is that colleges conform to the enterprises' appeal of core interests, that is, the colleges should enhance their appeal and take connotative development way. They must focus on three aspects: firstly, improving innovation ability and the ability to service enterprises and the society; secondly, strengthening the university-enterprise cooperation base and training talents in accord with the actual requirement of enterprises; thirdly, approaching the enterprise reality on the curriculum setting and talents training.

\subsection{Government Departments are Regarded as "Propeller" of University-enterprise Coopera- tion and their Role Needs to be Strengthened}

The survey results show that factors such as social environment, laws and regulations and social responsebility as external motivation promote enterprises to participate in university-enterprise cooperation. Though the relevant government departments have introduced many policies to promote the university-enterprise cooperation, the government still need to further strengthen the promoting function and create a good external conditions for the enterprises on the tax policy, public opinion direction, fiscal subsidy support even legislation, etc. It also need to build lasting, healthy and in-depth university-enterprise cooperation mechanism.

\section{Conclusion}

This paper, on the basis of research results, puts forward that the university-enterprise cooperation should adopt the "dynamic factor analysis". Finally, on the basis of the "dynamic factor analysis", the paper puts forward three suggestions that can improve cooperation strategy and way of university-enterprise and promote cooperation effect of university-enterprise in China's western areas.

\section{Acknowledgements}

This paper is supported by the reform subject - "oriented industry standard to declare at customs with international freight professional” "Bilingual, dual card, dual-energy technology" "the exploration and practice of course system construction" - of the education department in Guangxi; this paper is supported by the subject - "the study on the customs declaration serving North Gulf economic zone construction and on the personnel training mode of the international freight professional” - of Guilin Institute of Aerospace Industry.

\section{References}

[1] Xiong Rongsheng. Existing Problem Analysis on Cooperation of Higher Vocational Education in Our Country [J]. Journal of Education and Profession, 2008 (5).

[2] Ye Xiaoming \& Zhu Xuemei. China's Higher Vocational Education University-enterprise Cooperation: Model Characteristics and Practical Strategy. Modern Education Management [J], 2011 (4).

[3] Wang Yanli \& Xue Yaowen. Based on an Empirical Analysis of the Enterprises Perspective to Promote University-enterprise Cooperation Effect. Science Research [J], 2010 (7).

[4] Huang You. The Causes and Countermeasures of Enterprise Party Underpowered in Higher Vocational University-enterprise Cooperation. Mechanical Professional Education [J], 2007 (11)

[5] Outline of National Medium and Long-term Education Reform and Development Plan (2010-2020), 2010. 